\title{
Postoperative haemopneumothorax arising from an anomalous intercostopulmonary artery
}

\author{
RJ NELSON \\ From the Princess Margaret Hospital, Swindon
}

I report a postoperative haemopneumothorax resulting from the rupture of an anomalous intercostopulmonary artery.

\section{Case report}

A 34 year old man was admitted for an interval cholecystectomy six months after an acute attack of cholecystitis. Apart from occasional biliary symptoms his general health was excellent. He smoked 20 cigarettes a day but denied any previous history of respiratory disease.

On the morning of operation anaesthesia was induced with thiopentone $250 \mathrm{mg}$ and alcuronium $15 \mathrm{mg}$ and maintained by positive pressure ventilation with a mixture of 6 $\mathrm{V} / \mathrm{min}$ nitrous oxide, $3 \mathrm{l} / \mathrm{min}$ oxygen, and $0.5 \%$ halothane. A Manley ventilator was used with an average inflation pressure of $15 \mathrm{~cm} \mathrm{H}_{2} \mathrm{O}$. An uncomplicated cholecystectomy was performed and a total operative blood loss of $150 \mathrm{ml}$ was recorded. Before reversal of anaesthesia bilateral intercostal nerve blocks were induced from T7 to T10 with $30 \mathrm{ml} 0.25 \%$ bupivicaine with adrenaline. The patient's initial recovery was uneventful.

The following morning he complained of dyspnoea and severe left sided chest pain of sudden onset. He was found to be centrally cyanosed and profoundly shocked with a systolic blood pressure of $60 \mathrm{~mm} \mathrm{Hg}$ and an apex rate of $160 \mathrm{beats} / \mathrm{min}$. Examination of the chest indicated a left sided haemopneumothorax with gross mediastinal displacement (fig).

His immediate resuscitation required rapid transfusion and insertion of a chest drain, which removed $2500 \mathrm{ml}$ of blood. An urgent thoractomy was undertaken through the fifth left intercostal space. A further $700 \mathrm{ml}$ of blood and $500 \mathrm{ml}$ of old formed clot were evacuated from the pleural cavity. The source of continuing bleeding was traced to the torn end of a $2 \mathrm{~cm}$ length of artery, $2 \mathrm{~mm}$ in diameter, arising from the posterolateral aspect of the second intercostal space. The surrounding pleura and intercostal spaces were normal and in particular there were no extra pleural haematomas or puncture wounds. The left lung was collapsed. The haematoma was densely adherent to the apex of the upper lobe but there was no active bleeding point at this site. Haemostasis was secured by ligating and oversewing the vessel and the chest was closed with apical and

Address for reprint requests: Dr RJ Nelson, 33 Lexham Gardens, London W8. basal chest drains in position. The patient subsequently made an uncomplicated recovery.

\section{Discussion}

We believe the most likely sequence of events to have been as follows. In the immediate postoperative period a small left sided pneumothorax had been induced, as a result either of artificial ventilation or of the intercostal nerve blockade. This resulted in rupture of the anomalous vessel where it crossed the pleural space. The initial bleeding was light and represented by the $500 \mathrm{ml}$ of old clot found at thoracotomy. The following morning, as the patient was roused, an increase in respiratory effort decreased the intrapleural pressure and a secondary haemorrhage occurred.

The nature of the avulsed vessel is of some interest and several possibilities may be considered. Abnormal vascular connections of the lung are not rare and are almost certainly related to its complex embryological development. The circulation to the primitive lung bud arises from the dorsal aorta via the splanchnic plexus. The adult circulation is established by joining of the pulmonary arteries and

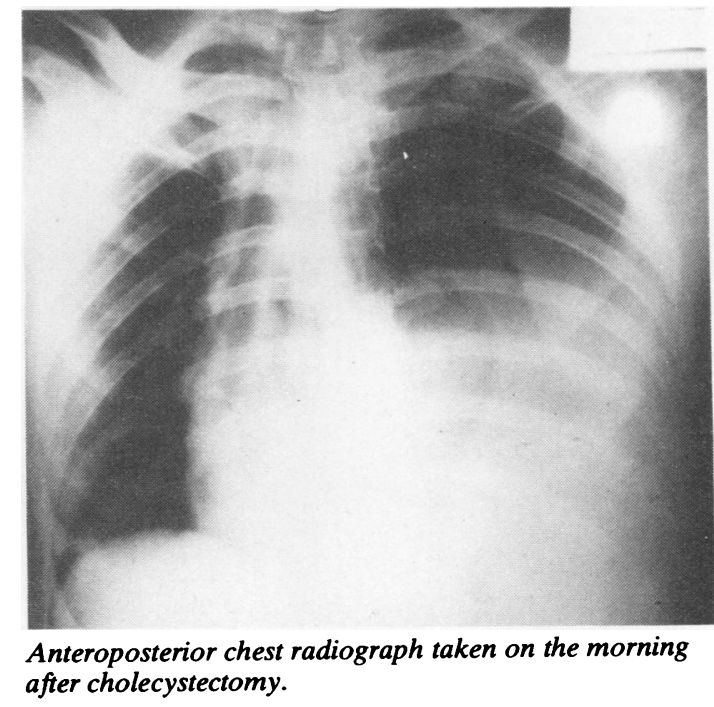


arches. At this stage the early systemic anastomoses usually atrophy and disappear. Persistence of these vascular connections results in anomalous vessels, which usually supply the lower lobes. ${ }^{2}$

The lung supplied may be normal ${ }^{3}$ or show the phenomenon of sequestration. ${ }^{45}$ These arteries commonly arise from the lower thoracic aorta or at the level of the coeliac axis. There have been reports of the high systemic origin of an artery to the basal segments of the left lung, ${ }^{6}$ but in search of the published reports no reference could be found to such a vessel passing either to normal or to sequestrated lung in the upper lobes.

The bronchial arteries develop several weeks later than the pulmonary arteries.' They arise from the dorsal aorta and accompany formation of the bronchial tree. Considerable variation exists in the number, level of origin, and course of these arteries. In their study of 150 cadavers Cauldwell $e a \mathbf{l}^{8}$ found that the left bronchial arteries arose from the anterior surface of the aorta or arch, less commonly from the right lateral or posterolateral aspect, and only rarely from the left surface. In only six cases $(4 \%)$ did a left bronchial artery arise in common with an intercostal artery and the latter was invariably a right intercostal artery. (This compares with a common right sided intercostobronchial stem in $78 \%$ of cases.) Cauldwell et al also state that "except in the rare cases of situs inversus bronchial arteries of either side have no relationship with the left intercostal vessels." Hellekant and Tylen,' however, have given elegant proof of the existence of a left sided intercostobronchial trunk.

Without angiography, which clearly could not be performed in our patient, it is impossible to know whether the torn vessel was part of an intercostopulmonary or a bronchial circulation. There have been reports of arteries growing through the pleura to enter the lung, but this appears to occur only when there are pleural adhesions such as may result from a thoracotomy. In the case described by Rees ${ }^{10}$ the patient also had Fallot's tetralogy. Our patient denied any respiratory symptoms or previous chest disease and his preoperative chest radiographs were entirely normal. We may speculate that an intrauterine event, such as a pulmonary infarct, may have caused a small area of pleural adhesion which allowed this artery to develop. Whatever its exact aetiology, it was the cause of a most unexpected postoperative complication, which could have been fatal.

I am grateful to Mr D Finch for his help with this case and to Mr EJC Wynne for allowing me to report it.

\section{References}

' Stark P, Meyer-Hammek, Nolte H, Kuke H. [Original paper in German.] Anaesthetist 1979;28:343-6.

${ }^{2}$ Cole FH, Alley FH, Jones RS. Aberrant systemic arteries to lower lung. Surgery, Gynaecology and Obstetrics 1951;93:589-96.

${ }^{3}$ Painter RL, Billig DM, Epstein I. Anomalous systemic arterialisation of the lung without sequestration. $N$ Engl $J$ Med 1968;279:866-7.

4 Ennis JT, Moule NJ, Woo-Ming M. Intralobar pulmonary sequestration in association with bilateral systemic arterialization of the lungs. Br J Radiol 1972;45:945-8.

5 Pryce DM. Lower accessory pulmonary artery with intralobar sequestration of lung: report of seven cases.J Pathol Bacteriol 1946;58:457.

${ }^{\circ}$ Hessel EA, Boyden EA, Stamm JS, Sauvage LR. High systemic origin of the sole artery to the basal segments of the left lung: findings, surgical treatment and embryologic interpretation. Surgery 1970;67:624-34.

7 Boyden EA. The time lag in the development of bronchial arteries. Anat $\operatorname{Rec} 1970 ; 166: 611-4$.

${ }^{8}$ Cauldwell EW, Siekert RG, Lininger RE, Anson BJ. The bronchial arteries: an anatomic study of 150 human cadavers. Surgery, Gynaecology and Obstetrics 1948;86:395-412.

9 Hellekant C, Tylen U. Left-side intercostobronchial trunk: a rare anomaly. AJR 1980;134:590-1.

${ }^{10}$ Rees S. Arterial connections of the lung. Clin Radiol $1981 ; 32: 1-15$. 